\title{
Huzurevinde Yaşayan 65 Yaş Üstü Yaşlılarda Ölüm Kaygısının Incelenmesi
}

\author{
Leman Kutlu $^{1 *}$, Gülcan Kendirkıran², Pınar Şeko ${ }^{3}$ \\ 1* İstanbul Atlas Üniversitesi, Sağlı Bilimleri Fakültesi, Hemşirelik Bölümü, İstanbul, Türkiye, (ORCID: 0000-0001-6393-8328), bilgileman@,gmail.com \\ ${ }^{2}$ Haliç Üniversitesi, Sağlık Bilimleri Fakültesi, Hemşirelik Bölümü, İstanbul, Türkiye (ORCID: 0000-0002-3243-9590), gulcank_87@hotmail.com \\ ${ }^{3}$ Haliç Üniversitesi, Sağlık Bilimleri Fakültesi, Hemşirelik Bölümü, İstanbul, Türkiye (ORCID: 0000-0002-7302-7605), pnrseko@gmail.com
}

(İlk Geliş Tarihi 4 Temmuz 2021 ve Kabul Tarihi 3 Kasım 2021)

(DOI: 10.31590 /ejosat.962359)

\begin{abstract}
ATIF/REFERENCE: Kutlu, L., Kendirkıran, G., Şeko, P. (2021). Huzurevinde Yaşayan 65 Yaş Üstü Yaşl1larda Ölüm Kaygısının İncelenmesi. Avrupa Bilim ve Teknoloji Dergisi, (27), 1032-1037.

$\ddot{O} \mathbf{z}$

Bu araştırma bir huzurevinde kalan 65 yaş üstündeki yaşlıların ölüm kaygısını ve ilişkili faktörleri incelemek amacıyla yapıldı. Kesitsel ve tanımlayıcı tasarımda olan bu çalışma Türkiyede'ki bir devlet huzurevinde kalan 65 yaşın üstündeki 108 gönüllü yaşlı sakin ile gerçekleştirildi. Araştırmanın verileri Şubat- Mart 2020 tarihleri arasında sosyodemografik özellikleri sorgulayan Kişisel bilgi formu ve ölüm kaygısını ölçen Templer Ölüm Kaygısı Ölçeği ile yüz yüze görüşme yöntemiyle toplandı. Verilerin istatistiksel analizinde tanımlayıcı istatistiksel analizler, bağımsız t testi, ANOVA, pearson korelasyon analizi, basit doğrusal regresyon analizi kullanıldı. Çalışmadaki yaşlılar 65 ile 95 yaşları arasında, ortalama 72,31 7,97 yaşında, çoğunlukla erkek, parçalanmış aile yapısına sahip, ilkokul mezunu, geliri giderinden az, çocuğu yok ve çocuğu olanların çoğunlukla bir çocuğu olduğu saptandı. Kadınların ölüm kaygısı puanlarının erkeklerin puanlarından istatistiksel olarak anlamlı derecede yüksek olduğu $(7,23 \pm 3,34: p<0.005)$ ve yaşlıların cinsiyetinin kadın olmasının ölüm kaygısı puanını 2,084 birim $(\beta=2,084, t=2,953, p=0,004)$ artırdığı saptandı. Diğer sosyodemografik özelliklerin ise ölüm kaygısı puanlarını anlamlı düzeyde etkilemediği saptandı $(\mathrm{p}>0,05)$.
\end{abstract}

Anahtar Kelimeler: Ölüm kaygısı, Yaşı, Huzurevi

\section{Investigation of Death Anxiety in Elderly People Over 65 and Living in Elderly Nursing Home}

\begin{abstract}
This study was conducted to examine the death anxiety and related factors of elderly residents over 65 years of age living in a elderly nursing home. This cross-sectional and descriptive study was conducted with 108 volunteer elderly residents over the age of 65 living in a government elderly nursing home in Turkey. The data of the study were collected by face-to-face interview method between February and March 2020, using a personal information form questioning sociodemographic characteristics and the Templer Death Anxiety Scale, which measures death anxiety. Descriptive statistics, independent-samples t test, ANOVA, pearson correlation analysis, simple linear regression analyses were used to analyze the data. It was determined that the elderly people in the study were between 65 and 95, average 72.31 \pm 7.97 years old most of them were male, divorced/widowed, had a broken family structure, primary school graduate, income less than expenditure, had no children, and most of those who had children had a child. It was determined that women's death anxiety scores were statistically significantly higher than men's scores $(7.23 \pm 3.34: \mathrm{p}<0.005)$ and that the gender of the elderly was female, increasing the death anxiety score by 2.084 units $(\beta=2.084, \mathrm{t}=2.953, \mathrm{p}=0.004)$. It was determined that other sociodemographic characteristics did not have a significant effect on death anxiety.
\end{abstract}

Keywords: Death anxiety, Elderly, Elderly nursing home

*Sorumlu Yazar: bilgileman@gmail.com 


\section{Giriş}

İnsan yaşamında son gelişim aşaması olan yaşlılık dönemi, 65 yaş ve üzerindeki bireyler için kullanılan bir yaşam evresidir. Yaşlılık, 65 yaş ve üzerindeki bireylerde, çökmenin ve gerilemenin başladığ1, yaşam sürecinin doğal ve zorunlu bir aşaması ve son safhasıdır (Aksoydan, 2008, Kaçan Softa vd., 2011).Türkiye İstatistik Kurumu, yaşlı nüfusun son beş y1l içerisinde \% 16 arttığını belirtmiş, yaşlı nüfus yaş grubuna göre incelendiğinde 2018 yılında \% 62,2'si 64-74 yaş grubunda, \% 28,6 's $175-84$ yaş grubunda ve \% 9,2'si 85 yaş ve üstü yaş grubunda yer aldığ1 görülmüştür (Türkiye İstatistik Kurumu: İstatistiklerle Yaşlılar, 2018). Yaşlılık; fiziksel ve psikolojik kayıpların olduğu, sosyal ilişkilerin azaldığı, yaşam döngülerinin son döneminde bulunmaları nedeniyle ölüme daha yakın hissedildiği ve ölüm kaygısının yoğun olduğu, ölümün kaçınılmazlığı ve kalan zamanının sınırlı olduğu gerçeğiyle yüzleşilen bir dönemdir (Erdoğdu ve Özkan, 2007; Aksoydan, 2008; Softa ve ark, 2011).

Ölüme yönelik yapılan düşünce ve sorgulama süreçleri yaşamı anlamlandırma çabası nedeni ile olduğu için geçmişten günümüze kadar ölüm üzerinde bütün bireyler çok düşünmekte ve bu konuda çalışmalar da yapılmaktadır (Kaçan Softa vd., 2011). Yaş faktörünün ölüm korkusunu etkileme durumu konusunda ortak bir fikir olmamakla birlikte (Öztürk vd., 2011), bireyin yaşam amacı ne kadar fazlaysa ölüm korkusunun da o kadar az olduğu belirtilmektedir (Zana et al., 2020). Ayrıca yaşlı bireyin sosyal desteğinin az olmasının da ölüm oranında artışa neden olduğu belirtilmektedir (Yerli, 2017). Yaşlı bireyde ölüme yönelik korku ve kaygı durumu kişi ölüm sürecini ve ölümden sonraki süreci düşündüğünde artış gösterebilmektedir (Mohammadpour et al., 2018).

Türkiye'de huzurevindeki yaşlılarla yapılan çalışmalar incelendiğinde; benzer çalışmaların olduğu, ölüm kaygısının bazı değişkenler açısından incelendiği, bu değişkenlerden elde edilen sonuçların yeterli sayıda olmadığı ve ölüm kaygısını etkileyen başka değişkenler açısından da desteklenmesi gerektiği görülmektedir. $\mathrm{Bu}$ gerekçe ve litaretür bilgisi doğrultusunda bu araştırmanın amacı, huzurevinde yaşayan 65 yaş üstü yaşlıların ölüm kaygısını incelemektir. Araştırmadan elde edilen sonuçların litaretüre katkı sağlayacağı ve huzurevinde çalışan sağlık profesyonellerine; ölüm korkusu olan yaşlıların, ölüm korkusu ile başa çıkmasında ve ölüm korkusu düzeyini en aza indirmede yaklaşımlar geliştirmesinde ve hemşirelik bakım sürecini planlamasında dikkatini çekeceği ve farkındalığını artıracağı düşünülmektedir.

\section{Materyal ve Metot}

\subsection{Evren ve Örneklem}

Örneklemin belirlenmesinde evreni belli örneklem belirleme formulü $\left(\mathrm{Nt}^{2} \mathrm{pq} / \mathrm{d}^{2}(\mathrm{~N}-1)+\mathrm{t}^{2} \mathrm{pq}\right)$ kullanıld $1(\mathrm{~N}=$ Evrendeki birey sayısı, $\mathrm{n}=$ Örnekleme alınacak birey sayısı, $\mathrm{p}=$ incelenen olayın görüş sıklığ $1=0,5, q=$ incelenen olayın görülmeyiş sıklığ $1(1-p)$ $=0,5, \mathrm{t}=$ Belirli serbestlik derecesinde ve saptanan yanılma düzeyinde bulunan $\mathrm{t}$ tablosundaki teorik değer $=1.96, \mathrm{~d}=$ Olayın görüş sıklığına göre yapılmak istenen $=0,05)$. Bu formüleg göre en az örneklem sayısı 177,18 olarak belirlendi. Ancak çalışmaya katılmak istemeyen sakinlerin olması nedeniyle bu sayı $(\mathrm{n}=108)$ evrenin \% 33'ünü temsil etti.
Örneklem seçiminde dahil olma kriterleri olarak; 65 yaş üstü olması, en az bir yıl huzurevinde kalması, çalışmaya katılmayı kabul etmesi, işitme, görme probleminin olmaması ve huzur evi tarafından yapılan mental testi geçmiş olması kriterleri arandı.

\subsection{Veri Toplama Araçları}

Araştırma verileri Şubat-Mart 2020 tarihleri arasında "Kişisel Bilgi Formu" ve Templer ve arkadaşları (1970) tarafından geliştirilen "15 maddelik Templer Ölüm Kaygısı Ölçeği (Templer ÖKÖ)" kullanılarak toplandı.

Kişisel Bilgi Formu; araştırmacılar tarafından geliştirilmiş olup yaşlıların sosyodemografik özelliklerini sorgulayan altı soru (yaş, cinsiyet, çocuk sahibi olma durumu, çocuk sayısı, aile yapısı, gelir durumu), huzur evindeki süreci sorgulayan üç soru (bakımevinde kalma süresi, ziyaretçisi olma durumu, ziyarete gelen kişiler) ve yaşlının sağlık durumunu sorgulayan dört soru (kronik hastalık durumu, hastalığın tanısı, daha önce hastaneye yatma durumu, hastaneye yatma nedeni) olmak üzere toplam 13 sorudan oluşmaktadır (Öztürk vd., 2011; Yerli, 2017; Azaiza et al., 2010; Dadfar et al. 2017).

Templer Ölüm Kaygısı Ölçeği; ölçek Templer ve arkadaşları tarafın 1970 yılında geliştirilmiş olup Türkçe geçerlik güvenirlik çalışması 2008 yılında Figen Akça tarafından yapılmıştır. Bireyin ölüm kaygısını ölçen 15 maddelik doğru yanlış şeklinde cevaplanan bir ölçektir. Puanlama yaparken 1., 4.ve 8-14 maddeleri doğru diğerlerini yanlış olarak düşünerek puan verilmesi gerekmektedir. Alınan her puan 1 olarak kodlanmaktadır. Doğru cevaplara 1 puan verilir, yanlış cevaplar 0 olarak puanlanır. Ölçeğin ilk 9 maddesi düz kodlanmış diğer maddeleri ise ters kodlanmış ifadeleri içermektedir. Ölçeğin puan aralığ1 0-15'tir. Ölçekten en düşük 0 puan, en çok 15 puan alınabilmektedir. 7 puan ve üstünün ölüm kaygısı yüksek, altının ise ölüm kaygısı düşük şeklinde yorumlanmaktadır. Ölçeğin Cronbach alfa sayısı 0.79 olarak belirtilmiştir (Akça ve Köse, 2008; Akça ve ark., 2011). Bu çalışmada ölçeğin Richard Kuderson 20 kat sayısı hesaplanmış ve 0,97 bulunmuştur. Ölçek bu çalışma için oldukça güvenilir bir ölçektir.

Çalışmanın evrenini 1 Şubat 2020-1 Mart 2020 tarihleri arasında bir devlet huzur evinde yaşayan 328 sakin, örneklemini ise çalışmaya dahil olma kriterlerine uygun 108 sakin oluşturdu.

\subsection{Verilerin Değerlendirilmesi}

Verilerin istatistiksel analizi IBM SPSS-22 programında yapıldı. Ölçeğin normal dağılım analizinde Shapiro Wilk, skewness, histogram, varyans homojenite testleri, yaşlıların sosyodemografik, sağlık ve huzur evindeki yaşam özelliklerinin analizinde; tanımlayıcı istatistiksel analizlerden ferkans, yüzde, ortalama ve standart sapma, karşılaştırmalarda ikili grupta bağımsız t testi, üç ve üstü gruplarda ANOVA, ilişkilerde; pearson korelasyon analizi, ve neden sonuç ilişkisini belirlemede de basit doğrusal regresyon analizi kullanıldı

\subsection{Etik İzinler}

Araştırmanın uygulanabilmesi için Haliç Üniversitesi Girişimsel Olmayan Klinik Araştırmalar Etik Kurulu'ndan etik onay (Protokol No:03/Karar No: 07/31.01.2020), Darülaceze idaresinden kurumsal izin, ölçeğin kullanılması için ölçek yazarlarından kullanım izni ve çalışmaya başlamadan önce de tüm katılımcılardan gönüllü bilgilendirme formu ile yazılı izin alınmıştır. 


\section{Bulgular}

Çalışmadaki yaşlıların sosyodemografik özelliklerinin dağılımında (Tablo 1); yaşlıların 65 ile 95 yaş arasında, ortalama $72,31 \pm 7,97$ yaşında, çoğunun erkek, boşanmış/dul olduğu, parçalanmış aile yapısına sahip, ilkokul mezunu, gelirinin kötü olduğu, çocuğu olmadığı ve çocuğu olanların çoğunun bir çocuğu sahip olduğu saptandı.

Sosyo demografik özelliklere göre Templer ÖKÖ puan ortalamalarının yaş, aile yapısı, çocuk sahibi olma durumu, çocuk sayısı, öğrenim durumu ve gelir durumuna göre istatistiksel olarak anlamlı farklılıklar göstermediği belirlendi $(\mathrm{p}>0,05)$.

Tablo 1.Yaşlıların Sosyodemografik Özelliklerine Göre Templer ÖKÖ Puanlarının Karşılaştırması (N=108)

\begin{tabular}{|c|c|c|c|c|c|}
\hline \multirow{2}{*}{$\begin{array}{l}\text { Sosyodemografik } \\
\text { Özellikler }\end{array}$} & \multicolumn{2}{|c|}{ Ort \pm SS } & \multicolumn{3}{|c|}{ Templer ÖKÖ } \\
\hline & & & $\mathbf{r}$ & $\mathbf{p}$ & \\
\hline \multirow[t]{2}{*}{ Yaş } & \multicolumn{2}{|c|}{$72,31 \pm 7,97$} & 0,014 & \multicolumn{2}{|l|}{0,885} \\
\hline & & & \multicolumn{3}{|c|}{ Templer's DAS } \\
\hline $\begin{array}{l}\text { Sosyodemografik } \\
\text { Özellikler }\end{array}$ & $\mathbf{N}$ & $\%$ & Mean \pm SD & $\mathrm{t} / \mathrm{F}$ & $\mathrm{p}$ \\
\hline $\begin{array}{l}\text { Cinsiyet } \\
\text { Kadın } \\
\text { Erkek }\end{array}$ & $\begin{array}{l}26 \\
82 \\
\end{array}$ & $\begin{array}{l}24.1 \\
75.9\end{array}$ & $\begin{array}{l}\mathbf{7 , 2 3} \pm \mathbf{3 , 3 4} \\
5,15 \pm 3,07\end{array}$ & 2,953 & ,004 \\
\hline Eğitim & & & & & \\
\hline $\begin{array}{l}\text { Okur Yazar } \\
\text { İlkokul } \\
\text { Ortaokul } \\
\text { Lise }\end{array}$ & $\begin{array}{l}19 \\
49 \\
20 \\
20\end{array}$ & $\begin{array}{l}17,6 \\
\mathbf{4 5 , 4} \\
18,5 \\
18,5\end{array}$ & $\begin{array}{l}6,00 \pm 3,77 \\
5,29 \pm 3,45 \\
5,20 \pm 2,51 \\
6,65 \pm 2,82\end{array}$ & 1,040 & ,378 \\
\hline $\begin{array}{l}\text { Aile yapısı } \\
\text { Çekirdek Aile } \\
\text { Geniş Aile } \\
\text { Parçalanmış Aile } \\
\end{array}$ & $\begin{array}{r}32 \\
8 \\
68 \\
\end{array}$ & $\begin{array}{r}29,6 \\
7,4 \\
\mathbf{6 3} \\
\end{array}$ & $\begin{array}{l}6,38 \pm 3,47 \\
5,75 \pm 3,41 \\
5,29 \pm 3,11 \\
\end{array}$ & 1,214 &, 301 \\
\hline $\begin{array}{l}\text { Çocuk sahibi } \\
\text { olma durumu } \\
\text { Evet } \\
\text { Hayır } \\
\end{array}$ & $\begin{array}{l}36 \\
72 \\
\end{array}$ & $\begin{array}{l}33,3 \\
\mathbf{6 6 , 7} \\
\end{array}$ & $\begin{array}{l}5,83 \pm 3,07 \\
5,56 \pm 3,35 \\
\end{array}$ & 0,417 & ,677 \\
\hline $\begin{array}{l}\text { Çocuk sayısı } \\
\text { (N=36) } \\
\text { Bir } \\
\text { İki } \\
\text { Üç ve üstü }\end{array}$ & $\begin{array}{l}13 \\
10 \\
10 \\
\end{array}$ & $\begin{array}{l}\mathbf{3 6 , 1} \\
27,8 \\
27,8 \\
\end{array}$ & $\begin{array}{l}6,54 \pm 2,67 \\
5,70 \pm 3,92 \\
5,23 \pm 2,80 \\
\end{array}$ & 0,590 &, 560 \\
\hline $\begin{array}{l}\text { Gelir Durumu } \\
\text { Kötü } \\
\text { Orta } \\
\text { İyi }\end{array}$ & $\begin{array}{r}72 \\
31 \\
5\end{array}$ & $\begin{array}{r}66,7 \\
27,7 \\
4,6 \\
\end{array}$ & $\begin{array}{l}5,85 \pm 3,463 \\
5,19 \pm 2,574 \\
5,60 \pm 4,159 \\
\end{array}$ & 0,435 & ,649 \\
\hline
\end{tabular}

Çalışmadaki yaşlıların huzurevindeki sürecine yönelik özelliklerinin dağılımında (Tablo 2); yaşlıların çoğunun kendi isteği ile yaşlı bakım evine geldiği, huzurevinde kalma süresinin 1 ile 38 yil arasında değiştiği, ziyaretçisi olduğu $(\% 72,2)$, ziyarete gelen akrabalarının ziyaretçi olarak ilk sırada (n:30) yer aldığ belirlendi.

Huzurevindeki sürecine yönelik özelliklere göre Templer ÖKÖ puan ortalamalarının; huzurevinde kalma süresi, ziyaretçisi olma durumu ve ziyarete gelen kişilere göre istatistiksel olarak anlamlı farklılıklar göstermediği saptandı $(\mathrm{p}>0,05)$.
Tablo 2. Huzurevindeki Sürece Yönelik Özelliklere Göre Templer ÖKÖ Puanlarının Karşılaştırması (N=108)

\begin{tabular}{|c|c|c|c|c|c|}
\hline \multirow{2}{*}{$\begin{array}{l}\text { Huzurevindeki } \\
\text { Sürece Yönelik } \\
\text { Özellikler }\end{array}$} & \multicolumn{2}{|c|}{$\operatorname{Ort} \pm$ SS } & \multicolumn{3}{|c|}{ Templer ÖKÖ } \\
\hline & & & $\mathrm{R}$ & $\mathrm{p}$ & \\
\hline \multirow{4}{*}{$\begin{array}{l}\text { Huzurevinde } \\
\text { kalma } \\
\text { süresi }\end{array}$} & & & 0,088 & ,364 & \\
\hline & \multicolumn{2}{|c|}{$5,73 \pm 6,75$} & & & \\
\hline & \multicolumn{2}{|c|}{$\begin{array}{l}\text { Min:1 } \\
\text { Mak:38 }\end{array}$} & \multicolumn{3}{|c|}{ Templer ÖKÖ } \\
\hline & $\mathrm{n}$ & $\%$ & Mean \pm SD & $\mathrm{t} / \mathrm{F}$ & $\mathrm{p}$ \\
\hline \multicolumn{6}{|l|}{$\begin{array}{l}\text { Ziyaretçisi olma } \\
\text { durumu }\end{array}$} \\
\hline Var & 78 & 72,2 & $5,72 \pm 3,195$ & 0,359 & ,721 \\
\hline Yok & 30 & 27,8 & $5,47 \pm 3,43$ & & \\
\hline \multicolumn{6}{|l|}{ Ziyarete gelen } \\
\hline \multicolumn{6}{|l|}{ Kişiler* } \\
\hline Gelen & 30 & 27,8 & $5,90 \pm 2,92$ & $-0,498$ & 619 \\
\hline Gelmeyen & 178 & 72,2 & $5,55 \pm 3,38$ & & \\
\hline \multicolumn{6}{|l|}{ Çocukları } \\
\hline Gelen & 14 & 13,0 & $6,36 \pm 3,65$ & $-0,875$ & ,384 \\
\hline Gelmeyen & 94 & 87,0 & $5,54 \pm 3,19$ & & \\
\hline \multicolumn{6}{|l|}{ Arkadaşlar } \\
\hline Gelen & 24 & 22,2 & $5,50 \pm 2,78$ & 0,252 & ,801 \\
\hline Gelmeyen & 84 & 77,8 & $5,69 \pm 3,38$ & & \\
\hline \multicolumn{6}{|l|}{ Kardeşler } \\
\hline Gelen & 26 & 24,0 & $5,58 \pm 3,28$ & 0,128 & ,899 \\
\hline Gelmeyen & 84 & 76,0 & $5,67 \pm 3,26$ & & \\
\hline
\end{tabular}

\section{*Birden fazla işaretlenmiştir.}

Çalışmadaki yaşlıların sağlık özelliklerinin dağılımında (Tablo 3); yaşlıların çoğunun, kronik hastalığının olduğu, kalp yetersizliği ve hipertansiyonun ilk sırada yer aldığı, daha önce hastaneye yattığ 1 , hastaneye yatış nedeninin ameliyat ve tedavi olduğu saptand1.

Yaşlıların sağlık Özelliklerine göre Templer ÖKÖ puan ortalamalarının kronik hastalığa sahip olma durumuna, hastalığın tanısına, daha önce hastaneye yatma durumuna ve hastaneye yatma nedenine göre istatistiksel olarak anlamlı farklılıklar göstermediği saptandı ( $\mathrm{p}>0,05)$.

Çalışmadaki yaşlıların Templer ÖKÖ puanlarının 0 ile 14 arasında değiştiği ve puan ortalamasının kesme puanından $(5,5 \pm 3,25<7)$ düşük olduğu saptandı. Kadınların puan ortalamalarının erkeklerin puan ortalamalarından daha yüksek, kesme puanın üstünde $(7,23 \pm 3,34>7)$ ve ölüm kaygısının olduğu saptand. Erkeklerin puan ortalamalarının ise kesme puanın altında $(5,15 \pm 3,07<7)$ ve ölüm kaygısının düşük olduğu belirlendi $(\mathrm{p}<0,05)$.

Kesme puana göre yapılan sınıflamada 27 (\%25) yaşlının ölüm kaygısı yaşadığı belirlendi. Ölüm kaygısı yaşayan bu yaşlıların ,\%66,7 erkek $(\mathrm{n}=18)$ ve puan ortalaması 9,83 $\pm 1,823$ 'dür. Kadınların oranı ise \% 33,3 (n=9) olup puan ortalaması $11,33 \pm 1,414$ 'dür.

Yaşlıların cinsiyet bağımsız değişkeninin Templer ÖKÖ puanlarına etkisini değerlendirmek amacıyla yapılan basit doğrusal regresyon analizi bulguları Tablo 4' verildi:

Templer ÖKÖ puanını 2.084 birim $(\beta=2,084, \mathrm{t}=2,953$, $\mathrm{p}=0,0007)$ artırmaktadır. 
Tablo 4: Templer Cinsiyetin Templer ÖKÖ ile Basit Regresyon Analizi

\begin{tabular}{lcccrc}
\hline Model & B & SE & $\boldsymbol{\beta}$ & T & P \\
\hline Costant & 5,146 & 0,346 & & 14,857 &, 000 \\
Cinsiyet-kadın & 2,084 & 0,706 & 0,276 & 2,953 &, 004
\end{tabular}

\begin{tabular}{llll}
\hline$R=0,276$ & $R^{2}=0,076$ & $F=8,718$ & $p=0,004$
\end{tabular}

Durbin-Watson $=2,312$

VIF: 0,276

Bağımlı değişken: Templer ÖKÖ

Bağımsız Değişken: Cinsiyet (Erkek:0, kadın:1)

\section{Tartışma}

Ölüm kaygısı doğal ve normal bir deneyimdir ve yaşam boyunca küçük bir düzeyde ölüm kaygısına sahip olmak bizi olumlu faaliyetlerde bulunmaya teşvik ederken anormal derecede yüksek bir ölüm kaygısı uyumsuzluğa ve korkuya yol açabilmektedir (Mohammadpour et al., 2018). Bazı yaşlı bireyler ölümden ve yaşlılıktan korkarken bazıları da yaşlılığın hayatın sonu olmadığını, bireylere ve topluma tecrübeleri ile katkı sağlayabilecek potansiyelde olduklarını düşünmektedirler (Shaw and Langman, 2017). Bir yandan, ölümün varlığı bir çok insan için doğal olsa da, birçok insan için de korkutucu ve kaygı vericidir (Wysokiǹski et al., 2019). Yaş ilerledikçe ölüm kaygısının arttığı (Sayın Kasar ve ark., 2016), erkeklerin ve kadınların ölümle ilgili olarak ölürken çekilen ızdırabın kendilerini korkuttuğu (Arpacı ve ark., 2011), yaşlı bireylerin kendi evlerinde ya da bir kurumda yaşamalarının da ölüm kaygısını etkileyebileceği belirtilmektedir. (Softa, 2015; Taycan, 2014). Litaretür ve bu araştırmanın amacı doğrultusunda huzuerevinde yaşayan 65 yaş üstü yaşlıların ölüm kaygısı sosyodemografik özellikler, sağllk özellikleri ve huzurevindeki yaşam süreci özellikleri açısından değerlendirilmiştir.

Literatürde yaşlı bireylerin ölüm kaygılarının sosyodemografik özelliklere göre karşılaştırmasında farklı sonuçların saptandığı ve bu sonuçlarda yaşam koşulları, çevresel faktörler ve bireysel farklılıkların etkili olduğu belirtilmektedir (Arpacı ve ark., 2011; Öztürk ve ark.,2011; Softa ve ark., 2011; Top ve ark., 2010)

Yaşla birlikte ölüm kaygısının arttığını, azaldığını, belli bir yaşa kadar artıp daha sonra azaldığını ve bir süre sonra belli bir düzeyde sabit seyrettiğini, yaşam öyküsü, sağlık durumu, sosyoekonomik durum ve yaşlanma sürecine uyumun da sonuçları etkilediğini belirten çalışmalar bulunmaktadır (Tang ve ark., 2002; Hayslip ve Hansson, 2003; Kastenbaum, 2007; Sinoff, 2017; Mohammadpour et al.,2018). Gümüş Demir'in (2020) yaptığı çalışmada ise anlamlı fark saptanmamıştır.

Ölüm kaygısının cinsiyete göre anlamlı farklılıklar göstermediğini belirten çalışmalar olmasına rağmen (Erdoğdu ve Özkan, 2007; Neimeyer ve ark., 2004; Top ve ark., 2010; Gümüş Demir, 2020) bazı çalışmalarda anlamlı farklılıkların olduğu; kadınların yaşlılığa bağlı olarak ortaya çıkan durumlara yönelik daha olumsuz algıya sahip olduğu, durumları üzerinde daha az kontrol hissettiklerini ve yaşlılık döneminde bağımlılıkları konusunda daha fazla endişelendikleri, kadınların daha duygusal bir yapıya sahip olmalarından ve duygularını daha rahat ifade edebilmelerinden kaynaklanabileceği belirtilmiştir (Madnawat ve Kachhawa, 2007; Karakuş ve ark., 2012;Mohammadpour et al., 2018).

e-ISSN: 2148-2683
Bu çalışmada kadınların ölüm kaygısı puanları erkeklerden anlamlı düzeyde yüksek saptandı $(7,23 \pm 3,34: \quad p<0.005)$. Katılımcıların \%25'inin ölüm kaygısı yaşadığı belirlendi. Ölüm kaygısı yaşayan yaşlıların $(\mathrm{n}=25)$ çoğunluğu erkek $(\% 66,7, \mathrm{n}=18)$ ve puan ortalaması $9,83 \pm 1,823$ 'dür. Kadınların (\%33,3, $n=9)$

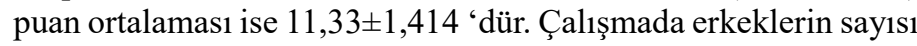
kadınlardan daha fazla olup huzurevlerinde yapılan diğer çalışmalarla da benzerlik göstermektedir (Birtane ve ark. 2000; Konak ve Çiğdem 2005).

Cinsiyet bağımsız değişkeninin ölüm kaygısı puanlarıyla yapılan analizi sonucunda anlamlı bir regresyon modeli olduğu $(\mathrm{F}=8,718, \mathrm{p}=0,004<0,05)$ ve bağıml değişkendeki varyansın \%7,6'sının $\left(\mathrm{R}^{2}=0,076\right)$ cinsiyet bağımsız değişkeni tarafından açıklandığı saptandı. Buna göre, cinsiyet bağımsız değişkeni ölüm kaygısı bağımlı değişkenini olumlu ve anlamlı olarak etkilemekte olup yaşlıların cinsiyetinin kadın olması ölüm kaygısı puanını 2,084 birim artırmaktadır.

Eğitim düzeyi yükseldikçe ölüm kaygısının azaldığını bildiren çalışmalar olmasına rağmen (Tang ve ark., 2002; Turgay, 2003) bazı çalışmalarda eğitim düzeyi ve ölüm kaygısı arasında anlamlı bir iliş̧ki olmadığı belirtilmiştir (Top ve ark., 2010).

Çocuk sahibi olmanın ve çocuk sayısının ölüm kaygısını etkilemediğini belirten çalışmalar olmasına rağmen (Özen, 2008; Gümüs Demir, 2020) bazı çalışmalarda anlamlı ilişki olduğu ve etkilediği belirtilmiştir (Erdoğdu ve Özkan, 2007; Öztürk ve ark., 2010).

Bu çalışmada, sosyodemografik özelliklere göre ölüm kaygısı puan ortalamalarının yaş, medeni durum, aile yapısı, çocuk sahibi olma durumu, çocuk sayısı, öğrenim durumu ve gelir durumuna göre anlamlı farklılıklar göstermediği belirlendi $(\mathrm{p}>0,05)$.

Yaşamın anlamının ve amaçlarının daha iyi anlaşılmasının, ölüm veya ölüme yakınlıkla ilgili kaygı ve olumsuz duyguları azaltabileceği veya ortadan kaldırabileceği vurgulanmaktadır (Zhang et al., 2019). Bazı çalışmalarda huzurevinde yaşayan yaşlılarda ölüm korkusunun huzurevinde yaşamayan yaşlılara oranla anlamlı derecede yüksek olduğu belirtilmiştir (Madnawat ve Kachhawa, 2007; Neimeyer, 2004; Azaiza et al.,2010).Baz1 çalışmalarda ise evde yaşayan yaşlı bireylerin ölüm kaygısı düzeyi huzurevinde yaşayan yaşlı bireylerden anlamlı düzeyde yüksek olduğu saptanmıştır (Arpacı ve ark., 2011; Kalkan ve Özdel, 2005; Gümüş Demir, 2020).

Bazı çalışmalarda yaşı bireylerin kurumda kalma süreleri ile ölüm kaygısı arasında anlamlı bir ilişki olduğu (Tang ve ark., 2002) bazı çalışmalarda ise anlamlı düzeyde ilişki olmadığı belirtilmiş̧ir (Köstek, 2015).Bu çalı̧̧mada yaşlı bireylerin ölüm kaygısı puanlarının düşük olduğu ve huzurevinde kalma süreleri ile ölüm kaygısı arasında anlamlı düzeyde ilişkisi olmadığı saptanmadi $(\mathrm{p}>0.05)$.

Bazı çalışmalarda medeni durumu evli olan yaşlı bireylerde ölüm kaygısının daha yüksek olduğu, eş ve çocuklara karşı sorumlulukların ve onları geride bırakma düşüncesinin bu duruma neden olduğu belirtilmektedir (Erdoğdu ve Özkan, 2007; Karakuş, 2012; Turgay, 2003). Bazı çalışmalarda ise medeni durumla arasında anlamlı bir fark olmadığı saptanmıştır (Öztürk ve ark., 2010; Top ve ark., 2010; Köstek, 2015; Softa ve ark.,2015; Gümüş Demir, 2020). Bu çalışmadaki yaşlı bireylerin çoğunun parçalanmış aile yapısına sahip olduğu, aile yapısına göre ölüm 
kaygısı puanları arasında anlamlı farklılık olmadığı ve aile üyelerinden çok akrabalarının ziyarete geldiği saptandı $(p>0,05)$.

Sosyal destekle ölüm kaygısı arasındaki ilişkiyi inceleyen bazı çalışmalarda sosyal destek artıkça ölüm korkusunun azaldığı belirtilmiştir (Yerli, 2017; Azaiza et al.,2010; Ron, 2004). Softa ve arkadaşlarının (2015) yaptığı bir çalışmada da medeni durum, çocuk sayısı, ziyaretçi gelme durumu, birlikte yaşanan kişi sayısı, yalnızlık durumu ile arasında anlamlı bir ilişki olmadığ saptanmıştır. Bu çalışmada da ziyaretçisi olan yaşlıların ölüm kaygısı puanlarının daha yüksek olmasına rağmen anlamlı düzeyde olmadığı saptandı $(\mathrm{p}>0.05)$.

Yaşlanma ile günlük yaşam aktivitelerini yerine getirmede fiziksel yetersizliler yaşanması, bilişsel becerilerin azalması ve kronik hastalıkların gelişmesi, yaşlıların ölüme bakış açılarını etkilemektedir (Ersanlı, 2008; Top ve ark., 2010; Yelboğa, 2017).

Bazı çalışmalarda yaşlı bireylerde ölüm kaygısı ile sağlık durumu arasında anlamlı fark olduğu; kronik hastalığının olması ve ciddi bir hastalığa yakalanmaktan korkma durumlarının ölüm korkusu ve ölüm anksiyetesini artırdığı, bazı çalışmalarda ise (Sayın Kasar ve ark.,2016; Saini et al., 2016; Kasar ve ark., 2016; Dadfar et al., 2017; Karahan ve Hamarta, 2019;), aralarında anlamlı fark olmadığı belirtilmiştir (Özen, 2008; Öztürk ve ark., 2011; Softa ve ark., 2011; Top ve ark., 2010 Köstek, 2015). Wysokiǹsk et al. (2019) tarafından yapılan çalışmada da kronik hastalığı olan katılımcıların, ölümün kaçınılmazlığının ve yaşamlarının son aşaması olduğunun daha fazla farkında oldukları için ölümü gereklilik olarak gördükleri belirtilmiştir. Ayrıca yaşlı bireylerin sağlık ile ilgili yaşadıkları olumsuzlar nedeni ile sürekli olarak ölüm korkusu yaşadıkları ve duaya, dinsel konulara yöneldikleri belirtilmektedir (Saini et al., 2016; Taghiabadi et al., 2017).

Karaca (2010) tarafından yapılan çalışmada da yaşlıları en mutlu eden şeyin ne olduğu sorulduğunda sağlıklı olmak ve yaşamak cevabının yüksek oranda olduğu belirtilmiştir. $\mathrm{Bu}$ çalışmada da yaşlıların sağlık özelliklerine göre ölüm kaygısı puan ortalamalarının kronik hastalığa sahip olma durumu ve daha önce hastaneye yatma durumuna göre anlamlı farklılıklar göstermediği saptandı $(p>0,05)$.

Karaca (2010) tarafından yapılan çalışmada huzuevinde kalan yaşlı bireylerin \%40'ının çocukları ile hiçbir zaman görüşmediği ve \%54,3'ünün birlikte yaşayacağı akrabası olmadığı ifade edilmiştir. Üstüner Top ve ark. (2010) tarafından yapılan çalışmada, yaşlı bireylerin huzurevinde kalma süreleri arttıkça ölüm kaygılarının arttığı belirtilmiştir. Softa ve arkadaşlarının (2015) yaptığı bir çalışmada ise ziyaretçi gelme durumu ile anlamlı bir ilişki olmadığı saptanmıştır. $\mathrm{Bu}$ çalışmada da huzurevindeki yaşam sürecine yönelik özelliklere göre ölüm kaygısı puan ortalamalarının; huzurevinde kalma süresi, ziyaretçisi olma durumu ve ziyarete gelen kişilere göre istatistiksel olarak anlamlı farklılıklar göstermediği saptandı $(\mathrm{p}>0,05)$.

Literatürde sosyodemografik özelliklerle ölüm kaygısı arasındaki ilişkilere ait sonuçların farklılık göstermesinin ölüm kaygısının çok boyutlu yapısından kaynaklanabileceği belirtilmektedir (Yelboğa, 2017, Gümüş Demir, 2020).

\section{Sonuç ve Öneriler}

Çalışmada kadınların ölüm kaygısı puanları erkeklerden istatistiksel olarak anlamlı derecede yüksek bulunmuştur $(7,23 \pm 3,34: \mathrm{p}<0.005)$. Yaşlıların cinsiyetinin kadın olması ölüm kaygısı puanını 2,084 birim $\quad(\beta=2,084, t=2,953, p=0,004)$ artırmaktadır. Yaş, medeni durum, aile yapısı, çocuk sahibi olma durumu, çocuk sayısı, öğrenim durumu ve gelir durumu, bakım evinde kalma süresi, ziyaretçisi olma durumu ve gelen ziyaretçiler, kronik hastalık durumu, hastalığın tanısı, daha önce hastaneye yatma durumu ve hastaneye yatma nedeninin ölüm kaygısı puanını anlamlı düzeyde etkilemediği saptandı $(p>0,05)$. Huzurevinde çalışan sağlık profesyonelleri; ölüm kaygısına yönelik çalışmaları periyodik olarak yapmalı, ölüm kaygısı yüksek olan bireylere yönelik başa çıkma yöntemleri konusunda destek vermeli, sosyal aktivitelere katılımını sağlamalı ve sosyal destek sistemleri ile bağlantı kurmasında yardımcı olmalıdırlar. Özellikle 24 saat birlikte olan hemşireler yaşama umudunun canlı tutulmasında önemli görevleri olduğunun bilincinde olarak yaşlıya özgü bakım sürecini planlanlarken ölüm kaygısının pek çok psikolojik ve fiziksel sorunun tetikleyicisi olacağının farkında olmalıdırlar.

Bu çalışmada ölüm kaygısını etkileyen değişkenlerden bazıları ile farklılıklar değerlendirilmiştir. $\mathrm{Bu}$ nedenle özellikle yaşlı bireyin huzurevindeki aktiviteleri ile huzurevinden memnuniyetine yönelik değişkenlerle de faklılıkların incelenmesi ölüm kaygısının daha iyi açıklanmasına katkıda bulunacağı düşünülmektedir.

\section{Teşekkür}

Darülaceze sakinlerine çalışmaya gösterdikleri ilgi ve katılımları için ve Darülaceze sakinleri ile buluşmamızda yardımcı oldukları için de tüm sağlık çalışanlarına teşekkür ediyoruz.

\section{Kaynakça}

Akça, F., Köse, İ. A. (2008). Ölüm Kaygısı Ölçeğinin Uyarlanması: Geçerlik ve Güvenirlik Çalışması. Klinik Psikiyatri, 11(1): 7-16.

Aksoydan, E. (2008). Yaşlılık ve Beslenme, Sağlık Bakanlı̆̆ Yayınlarl Yayın No:726, Şubat 2008,s:7.

Arpacı, F., Avdaş, E., Doğruöz, Ö., Sarıdoğan, T. (2011). Yaşlılarda ölüm kaygısının incelenmesi. Yaşlı Sorunları Araştırma Dergisi, 2:53-66.

Azaiza F., Ron P., Shoham, M Gigini I. (2010) Death and dying anxiety among elderly Arab Muslims in Israel, Death Studies, 34: 351-364, DOI: 10.1080/07481181003613941

Birtane, M., Tuna H., Ekuklu G., Uzunca K., Akçi C. \& Kokino S. (2000). Edirne huzurevi sakinlerinde yaşam kalitesine etki eden etmenlerin irdelenmesi. Geriatri, (3)141-145.

Curl, A., Fitt, H., Tomintz, M. (2020). Experiences of the built environment, falls and fear of falling outdoors among older adults: An exploratory study and future directions, International Journal of Environmental Research and Public Health (e-journal), 17(4): DOI:10.3390/ijerph17041224

Dadfar, M., Abdel-Khalek, A. M., Lester, D., Atef Vahid, M. K. (2017). The Psychometric Parameters of the Farsi Form of the Arabic Scale of Death Anxiety. Journal of Aging Research (ejournal), 7468217: DOI: 10.1155/2017/7468217 
Erdoğdu, M. Y. \& Özkan, M. (2007). Farklı dini inanışlardaki bireylerin ölüm kaygıları ile ruhsal belirtiler ve sosyodemografik değişkenler arasındaki ilişkiler. İnönü Üniversitesi Tip Fakültesi Dergisi, 14(3), 171-179.

Ersanlı, E. (2008). Yaşlıya Bakım Hizmetleri, Psikolojik, Sosyal ve Bedensel Açıdan Yaşlılık. Ankara: Pegem Akademi.

Gümüş Demir, Z. (2020): Yaşlı Bireylerde Ölüm Kaygısı İKSAD yayınevi, İstanbul.

Hayslip, B. \& Hansson, R. O. (2003). Death awareness and adjustment across the life span. Handbook of Death and Dying, (1), 437-447.

Kaçan Softa, H., Uçukoğlu, H., Ulaş Karaahmetoğlu, G., Esen, D. (2011). Yaşlılarda ölüm kaygısı düzeyini etkileyen bazı faktörlerin incelenmesi. Yaşlı Sorunları Araştırma Dergisi, 4(1-2): 67-79.

Kalkan, N. \& Özdel, O. (2005). Yaşl1lık, huzurevi ve yaşam yolculukları bir psikodrama grup çalışması. Türk Psikiyatri Dergisi, 16(2), 124-132.

Karaca, F. (2010). Huzurevinde kalan yaşlıların hayata bakış açıları ve gelecekle ilgili beklentileri. Aile ve Toplum, 6(22):50-72.

Karahan, F. Ş. \& Hamarta, E. (2019). Geriatrik olgularda kronik hastalıkların ve polifarmasinin ölüm kaygısı ve anksiyete üzerine etkisi. Ege Tip Bilimleri Dergisi, 2(1), 8-13.

Karakuş, G., Öztürk, Z. \& Tamam, L. (2012). Ölüm ve ölüm kaygıs1. Arşiv Kaynak Tarama Dergisi, 21(1), $42-79$.

Kastenbaum, R. (2007). Death anxiety. Arizona State University, Tempe AZUSA.

Konak, A., Çiğdem, Y. (2005). Yaşlılık olgusu: Sivas huzurevi örneği. Cumhuriyet Üniversitesi Sosyal Bilimler Dergisi, 29 (1), 23-63.

Köstek, G. (2015). Huzur ve bakımevinde yaşayan yaşlıların ölüm kaygısı ve benlik saygısının incelenmesi (Yüksek Lisans tezi). https://tez.yok.gov.tr

Madnawat, A. S., Kachhawa, P. S. (2007). Age, gender, and living circumstances: Discriminating older adults on death anxiety. Death Studies, 31(8), 763-769.

Mohammadpour, A., Sadeghmoghadam, L., Shareinia, H., Jahani, S., Amiri, F. (2018). Investigating the role of perception of aging and associated factors in death anxiety among the elderly. Clinical Interventions in Aging, 13, 405-410. DOI: 10.2147/CIA.S150697

Neimeyer, R. A., Wittkowski, J. \& Moser, R. P. (2004). Psychological research on death attitudes: An overview and evaluation. Death studies, 28(4), 309-340.

Özen, D. (2008). Huzurevinde yaşayan yaşlılarda ölüm kaygısının günlük yaşam işlevlerine etkisi. (Yüksek Lisans tezi). Erişim adresi: https://tez.yok.gov.tr.

Öztürk, Z., Karakuş, G., Tamam, L. (2011). Yaşıı Bireylerde Ölüm Kayg1s1. Anadolu Psikiyatri Dergisi, 12(1):37-43.

Saini, P., Patidar, A.,B., Kaur, R., Kaur, M., Kaur, J. (2016). Death anxiety and Its Associated Factors among elderly population of Ludhiana City, Punjab. Indian Journal of Gerontology, 30(1): 101-110.

Sayın Kasar, K., Karaman, E., Say, Şahin, D., Yıldırım, Y., Şenuzun Aykar, F. (2016). Yaşlı bireylerin yaşadıkları ölüm kaygısı ile yaşam kalitesi arasındaki ilişki. Gümüşhane Üniversitesi Sağllk Bilimleri Dergisi, 5(2): 48-55.

Shaw, R., Langman, M (2017). Perceptions of being old and the ageing process. Ageing Int, 42: 115-135. DOI 10.1007/s12126-017-9279-5.

Sinoff, G. (2017). Thanatophobia (Death Anxiety) in the elderly: The problem of the child's nability to assess their own parent's death anxiety state. Frontiers in Medicine (ejournal),4: DOI: 10.3389/fmed.2017.00011.

Softa, H. K., Karaahmetoğlu, G. U., Erdoğan, O. \& Yavuz, S. (2015). Yaşlilarda yaşam doyumunu etkileyen bazı faktörlerin incelenmesi. Yaşlı Sorunları Araştırma Dergisi, $8(1), 12-21$

Taghiabadi, M., Kavosi, A., Mirhafez, S. R., Keshvari, M., Mehrabi, T. (2017). The association between death anxiety with spiritual experiences aand life satisfaction in elderly people. Electronic physician, 9(3), 3980-3985. DOI: $10.19082 / 3980$.

Tang, C. S. K., Wu, A. M. \& W. Yan, E. C. (2002). Psychosocial correlates of death anxiety among Chinese college students. Death Studies, 26(6), 491-499.

Taycan, S. E., Kaya, F. D. \& Taycan, O. (2014). Psikiyatri polikliniğine başvuran bir grup yaşlıda huzurevi ya da aile ile kalmanın depresyon ve anksiyete düzeyine etkisi. Klinik Psikiyatri Dergisi, 17(2), 73-82.

Top, F. Ü., Saraç, A. \& Yaşar, G. (2010). Huzurevinde yaşayan bireylerde depresyon düzeyi, ölüm kaygısı ve günlük yaşam işlevlerinin belirlenmesi. Klinik Psikiyatri, 13, 14-22.

Turgay, M., (2003). Ölüm Korkusu ve Kişilik Yapısı Arasındaki İlişki. (Doktora tezi). Erişim adresi: https://tez.yok.gov.tr

Türkiye İstatistik Kurumu: İstatistiklerle Yaşılar (2018). https://hsgm.saglik.gov.tr/

Üstüner Top, F., Saraç, A., Yaşar, G. (2010). Huzurevinde yaşayan bireylerde depresyon düzeyi, ölüm kaygısı ve günlük yaşam işlevlerinin belirlenmesi. Klinik Psikiyatri, 13:14-22.

Wysokiński, M., Fidecki, W., Jarosz, M. (2019). Elderly people's acceptance of death: A study of a Polish Cohort. International Journal of Environmental Research and Public Health (ejournal), $2019 \quad$ 16(18), https://doi.org/10.3390/ijerph16183374

Yelboğa, N. (2017). Yaşlılıkta ölüm anksiyetesi. Journal of Current Researches on Health Sector, 7(2), 53-68

Yerli, G. (2017). Yaşlılık dönemi özellikleri ve yaşlılara yönelik sosyal hizmetler. Uluslararası Sosyal Araştırmalar Dergisi, 10(52): 1278-1287. DOI:10.17719/jisr.2017.1979

Zana, Á, Kegye, A., Czeglédi, E., Hegedűs, K. (2020). Differences in well-being and fear of death among female hospice employees and volunteers in Hungary. BMC Palliative Care (e-journal),19: DOI: 10.1186/s12904-02000550-z

Zhang, J., Peng, J., Gao, P., Huang, H., Cao, Y., Zheng, L., Miao, D. (2019). Relationship between meaning in life and death anxiety in the elderly: self-esteem as a mediator. $B M C$ geriatrics (e-jurnal),(1), https://doi.org/10.1186/s12877-0191316-7. 